\title{
AS DEMANDAS DA FORMAÇÃO DOCENTE SOB O OLHAR DOS PROFESSORES DA EDUCAÇÃO INFANTIL E DOS PRIMEIROS ANOS DO ENSINO FUNDAMENTAL
}

\author{
THE DEMANDS OF TEACHER TRAINING UNDER THE TEACHER'S VIEW OF CHILD \\ EDUCATION AND THE FIRST YEARS OF FUNDAMENTAL EDUCATION
}

\author{
M. M. SAMPAIO ${ }^{1,{ }^{*}}$, J. R. L. JARDILINO ${ }^{1,{ }^{*}}$ \\ 1 Universidade Federal de Ouro Preto, Instituto de Ciências Humanas e Sociais, \\ Programa de Pós-graduação em Educação, Brasil.
}

\author{
ARTICLE INFO \\ Article history: \\ Palavras-chave: Formação Docente. Demandas Formativas. \\ Received 2018-07-02 \\ Accepted 2018-08-17 \\ Available online 2018-08-31 \\ Desenvolvimento Profissional Docente. \\ Keywords: Teacher Training. Formative Demands. \\ Professional Development Teacher.

\section{*Autores correspondentes: \\ E-mail:anamendessampaio@yahoo.com; iriardilino@gmail.com}

\begin{abstract}
RESUMO. Essa comunicação discute as demandas de formação docente enfrentadas pelos professores da Educação Infantil e dos Anos Inicias do Ensino Fundamental da rede pública municipal da cidade de MarianaMG. Nessa direção, são apresentados os resultados parciais de uma pesquisa de Mestrado em Educação intitulada "Demandas de desenvolvimento profissional docente no município de Mariana-MG: PNE (20142024) e PME (2015-2024), desenvolvida na Universidade Federal de Ouro Preto - MG. Trata-se de um estudo exploratório de abordagem qualitativa, que se utilizou da técnica de grupo focal e análise documental de políticas de formação e valorização docente. A pesquisa aponta que as demandas de formação dos professores relacionam-se com as lacunas inerentes a formação inicial; com elementos objetivos da carreira, a exemplo das condições de trabalho; com a falta de valorização docente, tendo em vista que os professores não são apreciados acerca de suas demandas formativas; bem como com as dificuldades de oferta e a falta de incentivo à formação continuada.
\end{abstract}

\begin{abstract}
This communication discusses the demands of teacher education faced by the teachers of Early Childhood Education and Early Years of Elementary School of the municipal public network of the city of Mariana-MG. In this direction, we present the partial results of a Master's in Education research entitled "Demands for professional development in the county of Mariana-MG: PNE (2014-2024) and PME (20152024), developed at the Federal University of Ouro Preto - MG. This is an exploratory study of a qualitative approach, using the focus group technique and documentary analysis of training policies and teaching valorization. The research points out that the demands of teacher training are related to the gaps inherent in initial training; with objective career elements, such as working conditions; with the lack of teacher appreciation, given that teachers are not appreciated about their training demands; as well as the difficulties of supply and lack of incentive for continuing education.
\end{abstract}

\section{Introdução}

Professores, estudiosos e pesquisadores da área educacional vêm continuamente discutindo a formação docente como um dos aspectos mais relevantes para o processo de DPD - 
Desenvolvimento Profissional Docente. Para muitos destes, mudanças na concepção e estruturais dos cursos de formação (inicial e continuada) podem alavancar a qualidade da educação do país, ainda que percebam que essa formação, por si só, não alcançaria grande êxito nessa ambiciosa empreitada. Este trabalho tem como propósito apresentar os resultados parciais de uma pesquisa, que buscou, por meio de discussões entre professores investigados, conhecer a respeito das demandas formativas desses profissionais.

Atualmente, percebe-se que as exigências trazidas pelo novo contexto sócio educacional, cada vez mais pós-industrial e pós-moderno, vêm se instaurando como fio condutor para se repensar a formação docente, as mudanças nos novos processos de ensinar e aprender, como também o desenvolvimento profissional dos professores, que se configura como elemento chave para lidar com este novo formato de processo educativo.

Para compreender essas novas necessidades e mudanças que se impõem ao trabalho docente, é imprescindível ouvir esses sujeitos no tocante a sua formação, inclusive como esforço redobrado para, diante das adversidades, continuar a aprender. Nesse aprendizado, destaca-se a importância da prática profissional, tendo em vista que, sem ela, o professor não alcança as experiências necessárias para se colocar frente às situações impostas pela sociedade e pelo regime educacional. Em meio a essa condição, a escola deve tornar-se um lugar de conquistas, já que por meio dela, o professor pode lograr um "espaço autônomo, um espaço que é seu, onde ele possa transitar com certa liberdade" (RAMALHO; NUÑEZ; GAUTHIER, 2003, p.54). Trata-se ainda do lugar onde a sociedade pode reconhecer a relevância de seu trabalho. Ou seja, é na prática docente que se caracteriza a sua profissionalidade, na medida em que nela ocorre a "racionalização dos saberes e das habilidades utilizadas no exercício profissional" (RAMALHO; NUÑEZ; GAUTHIER. 2003 p. 53).

Assim, a partir da construção e reconstrução de concepções, valores e crenças que ocorrem dentro da dinâmica de uma organização educacional, os professores alcançam a possibilidade de constituir um conjunto de elementos em rede, ligado: a) à sua formação inicial b) às suas experiências num contexto educativo; $c$ ) às suas condições de trabalho; d) aos projetos e incentivos de formação continuada que lhes são ofertados e e) à sua valorização profissional.

Para realização dessa pesquisa de abordagem qualitativa, foram utilizados os seguintes procedimentos metodológicos: 1) realização de grupos focais com 27 professores da Educação Infantil e dos Anos Iniciais do Ensino Fundamental que atuam em escolas da zona rural e urbana do sistema público municipal de educação da cidade de Mariana - MG; 2) análise documental de políticas de formação e valorização docente, a exemplo das presentes no PNE (Lei 13.005/2015) e no PME (Lei 3.042/2015) e 3) aplicação de questionário de caracterização dos docentes investigados. As falas desses docentes apresentam aspectos importantes relacionados às suas demandas formativas, frente ao atendimento das novas exigências sócio educacionais enfrentadas por esses profissionais. 


\section{Demandas da Formação: o que dizem os professores?}

A concepção de formação a partir da ideia de desenvolvimento profissional docente ainda é bastante recente. Para Nóvoa (1995) o que era visto em todo o mundo, até então, tratava-se de uma ríspida desprofissionalização dos professores:

Os anos 60 foram um período onde os professores foram ignorados, parecendo não terem existência própria, enquanto aspecto determinante da dinâmica educativa; nos anos 70 , os professores foram esmagados, sob o peso da acusação de contribuírem para a reprodução das desigualdades sociais; já nos anos 80 multiplicaram as instâncias de controle dos professores, em paralelo com 0 desenvolvimento de práticas institucionais de avaliação (NÓVOA, 1995, p.15).

Assim, somente em meados da década de 80 , os professores passam a ocupar um papel de destaque nas discussões, debates e pesquisas educacionais. Questões como carreira, trajetória da profissão, proletarização do magistério, valorização dos professores, saberes docentes, desenvolvimento profissional, bem como as demandas formativas, passam a ocupar lugar de destaque na literatura educacional.

A respeito dessa última, percebe-se que dentre as diversas atribuições impostas atualmente aos docentes, fica cada vez mais claro que as dificuldades em aprender a ser professor vêm exigindo desse profissional uma série de novas habilidades, capacidades e conhecimentos, frente a situações complexas que emergem da sua prática pedagógica diária. Nesse contexto, faz-se necessário compreender e analisar o que os professores expõem a respeito de suas formações. Segundo o professor P5 e P2:

Eu acho que a minha formação de magistério ela foi uma questão mais prática, o que eu iria fazer na sala de aula. Para aquele momento, ela era válida, era o que se tinha com relação a isso. Já a minha formação, a minha graduação, eu acho que ela foi falha. Ela não me atendeu no nível que eu gostaria. Hoje, o que a gente vê, é que muita coisa ficou pra trás, que ela poderia ter sido melhor (P5).

Eu acho incompleta, porque pelo menos quando eu estudei muitos temas não eram abordados (P2).

A ideia trazida na fala do professor P5 aponta para as novas demandas de formação docente diante da antiga formação de magistério, em nível médio. Destaca-se, que as mudanças educacionais apontadas no séc. XXI vêm requerendo da profissão de professor maiores conhecimentos, ideias, habilidade nos procedimentos, nas estratégias de ensinar, de conviver com os alunos e com a comunidade escolar e de desenvolver diferentes atitudes, valores e hábitos. Uma nova concepção pedagógica que atenda todas essas mudanças, exige não apenas a ampliação de certos caminhos pré-estabelecidos, mas também um exercício profissional que inclui autonomia, senso crítico e capacidade de decisão.

Porém, o que se percebe é que apesar de ter passado mais de uma década da exigência do diploma de licenciatura em nível superior para o exercício do magistério, trazida pelas disposições transitórias da LDB (1996), os cursos de pedagogia, bem como das demais licenciaturas, continuam sofrendo severas críticas, tanto no meio acadêmico, como por parte dos professores da educação básica, quanto à qualidade da formação ofertada, principalmente quando se trata do antigo empasse relacionado à teoria e a prática. 
Essa realidade vem mostrando que, se por uma um lado aumenta-se as exigências sobre os docentes por melhores índices educacionais, por outro lado considera-se que o problema da educação reside, sobretudo, no déficit formativo dos professores. Para Scheibe (2010), as severas críticas aos docentes revelam os professores como mal formados e pouco engajados de suas atribuições e responsabilidades para o êxito dos alunos. Entretanto, o que prevalece, segundo Gatti e Barreto (2009), são condições de formação distanciadas do satisfatório e pouca articulação dos entes federados (União, Estados, Municípios e DF) em executarem políticas públicas de formação docente que reconheçam o professor como ator principal no desenvolvimento de sua prática pedagógica, como construtor e reconstrutor de conhecimentos a partir do seu percurso formativo e profissional e da sua prática, conforme suas necessidades e experiências.

$\mathrm{Na}$ visão dos professores, a distância entre o que se aprende nos bancos das IES Instituições de Ensino Superior e a realidade encontrada na escola é outro ponto de destaque no processo formativo inicial. Isso porque os cursos de pedagogia, entrada principal para a profissão, não contempla "o quê" e o "como" ensinar em um contexto educativo tão heterogêneo e diverso. Além de não preparar para a realidade escolar. Para o professor P21:

[...] Nem se falava que todo mundo aprendia de maneira diferente. A ideia que se passava é que você entrava na sala de aula e ia encontrar meninos com a mesma capacidade, cheios de vontade de aprender, que você ia planejar sua aula, chegar lá e dá uma aula bacana. Só que, depois que você chega à sala de aula, percebe "puxa vida, não é isso que eu pensava". É difícil! (P21).

Apesar da aparente obviedade do preceito de que o professor, por excelência, é o profissional que sabe ensinar e tem domínio sobre os conteúdos que leciona, infelizmente isso não se confirma no cotidiano da prática, e um dos seus maiores motivos é a formação inicial. Segundo Gatti (2009), o curso de Pedagogia, que deveria garantir a competência de quem leciona na Educação Infantil e nos primeiros anos do Ensino Fundamental, forma profissionais despreparados para planejar, ensinar e avaliar, como, também, para compreender o contexto social à sua volta. $O$ resultado é a péssima qualidade da educação no país.

A ideia de classes homogêneas e alunos "cheios de vontade para aprender" (P21), bem como a falta de uma maior compreensão do contexto escolar em nível pedagógico, administrativo e comunitário leva os professores a serem surpreendidos, tendo em vista que suas formações e suas "passagens" pelas escolas, realizadas em períodos de estágio, não vêm dando conta de compreender questões fundamentais à sua formação. Segundo Gatti (2013):

A educação é processo que envolve necessariamente pessoas com conhecimentos em níveis desiguais propondo-se a compartilhar esses conhecimentos. A educação escolar é uma ação intencional que pressupõe a atuação de um conjunto geracional com outro mais jovem, ou com menor domínio de conhecimentos ou práticas, na direção de uma formação social, moral, cognitiva, afetiva e, num determinado contexto histórico, social e institucional (GATTI, 2013, p.52).

Dessa forma, é preciso rever a formação dos professores, compreendendo as práticas educacionais como processos de fundamentos teóricos, sem perder de vista o alerta de Gatti (2013), para o fato de que as práticas geram teorias e as teorias geram as práticas, em movimento 
recursivo. Infelizmente, essa relação dialética não é mantida nas estruturas universitárias e curriculares do país. O que se teima em conservar é uma concepção de ciência positivada, em que:

As abstrações imperam como tópicos em vasos não comunicantes: conhecimento da ciência isolado do conhecimento pedagógico-educacional, que por sua vez continua distante da realidade social, estes dois últimos sempre considerados como de menor valor (GATTI, 2013, p.54).

O importante desta questão é que a prática aprendida na experiência esteja associada integralmente a teoria discutida em sala de aula. Assim, o currículo do curso de pedagogia precisa adequar-se às necessidades formativas dos professores, a fim de que eles possam desempenhar as atividades que os esperam, sem tantas surpresas. Nessa trajetória, a prática dos estágios se torna uma chave importante, por criar oportunidades de relacionar a teoria com a prática, bem como de conhecer a realidade dos problemas inerentes ao contexto em que o professor irá atuar. Sobre essa questão, o professor P2 afirma que os estágios vêm ocorrendo de forma falha, não cumprindo o importante papel que the cabe:

Outro ponto que eu acho é a questão do estágio. Acho também que não proporciona muito aprender. Porque você vai lá, fica um período, mas tem muitos alunos (licenciandos) que até se assustam com o que veem. Principalmente na questão da disciplina, de como manter uma turma focada, a pessoa acaba até desistindo do curso de pedagogia por causa disso [...]. Então, eu acho que o estágio é muito falho nesse ponto. E muito pouco (P2).

A respeito dos estágios, Gatti (2016) enfatiza que em grande parte das licenciaturas o seu programa e controle são inconsistentes, em que a simples observação de aula, quando realizada, trata-se da atividade mais sistemática a ser considerada. Como agravante, a autora destaca que:

Quando os cursos funcionam em período noturno é flagrante a falta de tempo para os alunos cumprirem as horas exigidas de estágio dado que, em geral, trabalham o dia todo. E, justamente uma das características atuais dos cursos de formação de professores é o aumento crescente das matrículas no turno noturno (GATTI, 2016, p.167).

No que se refere à formação continuada dos professores, achou-se necessário compreender como se dá oferta desse tipo de formação, bem como os incentivos e o suporte pedagógico que os professores possuem para continuarem se formando ao longo de suas carreiras. Verificou-se, portanto, que a SME - Secretaria Municipal de Mariana - MG não possui um Programa de Formação Continuada Docente, responsável pelo planejamento e execução das ações formativas oferecidas aos profissionais da educação básica municipal. A respeito dessa questão, o professor P1 ressalta que a falta de um planejamento por meio de um programa específico de formação docente coordenado pela SME vem deixando esses profissionais inseguros em apostarem na realização dos cursos de que têm interesse.

O que eu penso é que toda vez que fosse ter um curso de capacitação para melhorar qualquer profissional, que a rede já tivesse um programa. Ah, vai ser esse curso que você vai fazer. Então, você entra. Sabe? Qualquer coisa combinada já! É o planejamento [...]. A gente fica perdido! Você não faz a inscrição e você não sabe se você vai poder fazer (P1).

Quanto à oferta dos cursos de formação, os professores investigados apontam que desde o ano de 2015, estes cursos, ora não veem sendo ofertados, ora são apenas divulgados, ora são ofertados com implicadores para sua realização. Segundo estes professores: 
Não oferta! Oferta? Para mim, não! (P2).

Nos últimos dois anos está raríssimo, raríssimo. Até o ano atrasado eles tentavam fazer algumas palestras (P3).

Pelo que eu tenho de entendimento a prefeitura não oferece. No momento, não! Eu não sei de nenhum curso de formação em andamento (P10).

Ela divulga, mas ela não oferta. E quando é oferecida também, fala que é para quem está em tal série. É selecionado, então! (P15).

Diante dos excertos, compreende-se que a falta de um programa municipal contínuo de formação dificulta a formação continuada dos professores, devendo, portanto, ser questão importante a ser repensada pelo governo local. Por outro lado é importante destacar que nos últimos anos o governo federal ampliou a oferta de ações para a formação continuada dos professores da Educação Básica. No que diz respeito aos programas do Governo Federal, cabe ao poder municipal efetivar a parceria e fornecer condições de estrutura e de pessoal para a participação dos professores, nos moldes determinados pelas diretrizes dos referidos cursos. Mesmo que estas ações se mostrem como uma resposta fragmentada às demandas formativas dos docentes, é necessário reconhecê-las e examiná-las. Vale destacar, que os professores não indicaram a participação atual em nenhum programa de formação continuada ofertado em nível nacional.

Segundo Gatti, Barreto e André (2011) é nítida a intenção do governo federal em implantar um sistema nacional de educação, assumindo maior responsabilidade pela formação dos professores, através de políticas que envolvem os entes federados. Porém, o que se tem presenciado até o momento são iniciativas frágeis, fundadas apenas nos aspectos técnicos da formação, não atingindo necessariamente o desenvolvimento profissional desses docentes.

Observa-se, ainda, que a adesão aos cursos ofertados pela SME, não ocorre segundo o grau de interesse dos docentes, estando sujeita a critérios pré-estabelecidos por essa mesma secretaria. A falta de número de vagas suficientes, também, é trazida na fala do professor P22, como obstáculo para aqueles professores que se sentem motivados a participar de determinado curso. Já para o professor P26, na maioria das vezes, a escolha dos participantes em determinados cursos de formação é realizada em torno dos interesses da SME e aqueles cursos em que todo o quadro docente é convidado, ou, até mesmo, "obrigado" a participar, tratam-se de capacitações de baixa carga horária. Como mostra os professores P22 e P26.

A prefeitura também oferece, mas eu vejo que, às vezes, o que tá acontecendo muito agora é que, às vezes, a gente tem até interesse de ir, mas é estipulado o número de participantes. Aí, por exemplo, "nossa tem um curso excelente", mas eu não posso ir (P22).

E na maioria das vezes já têm aqueles escolhidos a dedo que vão fazer os cursos. Os melhores cursos a gente não tem acesso, a demanda não chega a nós. A gente vai em curso quando a prefeitura oferece um curso de capacitação de um dia, onde a rede toda é obrigada a participar. Não é um curso 180 horas, ou uma pósgraduação (P26).

O desordenamento na adesão dos professores aos cursos de formação, bem como as indicações com critérios desconhecidos pelos professores criam um clima de insatisfação e um sentimento de desvalorização por parte dos docentes. Desse modo, infere-se que a falta de um programa de formação realizada pelo município, com oferta ampla aos professores, respaldada pela presença de especialistas nas diversas áreas específicas das disciplinas do currículo comum e por 
grupos de estudos em áreas de atuação como educação infantil, alfabetização, educação especial etc., em muito poderia ajudar para resolver esses empasses. Porém, duas questões se tornam fundamentais nesse processo, a primeira é que formar um grupo de profissionais com esse perfil demanda investimento financeiro e projeto de longo prazo da gestão educacional. A segunda, é que esse tipo de iniciativa requer da responsabilidade gestora que o programa se dê como concluído no município, somente quando tiver sido oportunizada a toda rede de ensino, a devida participação.

Importante acrescentar, que muitas secretarias municipais de educação não dispõem de recursos financeiros e estruturais. Assim, na maioria das vezes, o staff delas, responsável pela formação continuada dos docentes, se resume a um grupo de servidores da área operacional e burocrática que realizam contratações de cursos para formação da rede. Esses são motivos, quase sempre, levam as secretarias de educação a recorrer aos cursos e programas ofertados pelo MEC e/ou pelas universidades públicas. De acordo com pesquisa realizada por Gatti, Barreto e André (2011), grande parte das secretarias municipais de educação não possui, sequer, um departamento direcionado à formação continuada dos professores. Esta realidade, também, pode ser vista no trabalho de Davis, Nunes e Almeida (2011). Consequência da cruel desigualdade econômica do país.

No levantamento de dados realizados, foi possível perceber que os professores não se sentem incentivados a realizarem cursos de formação continuada e trazem diversas questões relacionadas a essa falta de incentivo. Uma delas refere-se à liberação dos docentes, por parte da SME, para realização desses cursos. Como mostra a fala dos professores P18 e P22:

Eu queria fazer o curso também e não fiz porque falaram que não podia liberar (P18).

Ass vezes, nem consegue saber se vai ter esse suporte da escola ou da Secretaria. Igual, nós duas. Conseguimos esse curso de neurociência, mas a gente ainda está esperando para saber se a gente vai conseguir ir no curso ou não (P22).

Necessário destacar, que a Lei Complementar 139/2014 (MARIANA, 2014), que dispõe sobre o Plano de Carreira dos Profissionais do Magistério da cidade de Mariana-MG, regulamenta o afastamento para formação docente, apenas em casos de pós-graduação stricto sensu, não reservando a esse profissional o pagamento integral de suas remunerações e sim o de uma bolsa no valor do piso salarial vigente ${ }^{1}$ da prefeitura. Fato que não incentiva os professores a darem continuidade as suas formações.

Assim, verifica-se que o texto da referida lei, não prevê a liberação dos professores para a realização de cursos de curta duração que, na maioria das vezes ocorre de forma esporádica. Esta realidade não se caracteriza como incentivo à formação continuada e diverge da Estratégia 18.4 do PME de Mariana (Lei 3.042/2015, p.28, grifo nosso) que trata a respeito de "assegurar licenças remuneradas e incentivos para qualificação profissional, inclusive em nível de pós-graduação stricto sensu". Apesar da estratégia não especificar que tipo de incentivo será dispensado, infere-

\footnotetext{
${ }^{1} \mathrm{O}$ piso salarial vigente na prefeitura municipal de Mariana - MG possui o mesmo valor do salário mínimo nacional, que é de $\mathrm{R} \$ 937,00$.
} 
se que por meio do termo "inclusive" trazido em letra de lei pelo PME, torna-se necessário rever de que forma pode ocorrer a liberação para outros cursos, além do mestrado e doutorado.

Outra questão em torno da falta de incentivo à formação continuada, revelada pelos professores, aponta para a existência de um quadro reduzido de docentes atuando nas escolas da rede municipal de Mariana. Desse modo, a falta de professores substitutos é um fator agravante, que deve ser considerado. Como pode ser visto nas falas dos professores P27, P16 e P20:

$\mathrm{Na}$ verdade, o que foi colocado, realmente, vários profissionais estão afastados. Então, às vezes, nem as pessoas da manhã poderiam, ou essas da manhã, também, estariam fazendo. A dificuldade está aí, em liberar. Não porque a escola não quer liberar, e sim porque não tem pessoas para ficar substituindo (P27).

Nós estamos com problemas de profissionais que são poucos, agora não tem nem eventual, aqui à tarde [...]. Não tem como um profissional não ficar na sua sala para você fazer curso ou então você vai fazer no horário que não é para você estar na escola (P16).

Mas eu vejo um problema sério, que é a questão da falta de valorização de quem busca formação [...]. O professor busca formação e aí tem esse problema: que não tem ninguém que o substitua. Você tem que ir buscar formação fora do seu horário, o que é complicado! Quem tem três turnos, igual à gente estava conversando no outro dia: "vou estudar que horas? vou fazer curso que horas? de madrugada?". Porque não posso largar a sala de aula, não posso largar meu horário de pedagogia, não tem quem substitua. Esse é um problema! (P20).

Esta realidade, trazida pelos professores, corrobora as pesquisas de Gatti, Barreto e André (2011), ao registrarem que dentre as dificuldade mais recorrentes apontadas pelas Secretarias de Educação é justamente a retirada do professor da sala de aula, em decorrência de sua substituição, a fim de que os alunos não fiquem sem aula. Esse mesmo exame é realizado por Davis, Nunes e Almeida (2011, p. 95): "[...] faltam professores substitutos, quando os docentes se afastam da sala de aula para participar de ações de Formação Continuada e muitas Secretarias de Educação reclamam de que não dispõem de um centro de formação próprio [...]".

A ausência de professores substitutos sugere a possibilidade de que a formação seja realizada fora do horário de trabalho, o que se torna, ainda, mais agravante para os professores com extensa carga laboral, a exemplo da fala trazida pelo professor P20. Entretanto, na análise dessa possibilidade, é importante atentar que as orientações dos Referencias para a Formação de Professores (BRASIL, 2002, p.135), afirma caber às secretarias de educação "a criação de condições para que a formação continuada possa ocorrer dentro da jornada regular de trabalho dos profissionais da educação, sem prejuízo das horas de docência". Essas orientações parecem observar a realidade da carga laboral experenciada por muitos docentes, conforme revela 0 depoimento do professor P25:

Infelizmente professor trabalha além. Ele trabalha como se fossem três turnos: de manhã à tarde e quando chega em casa ele tem que fazer as coisas da casa, leva serviço de escola ainda para fazer em casa e aí a gente não tem tempo para nada! (P25).

A percepção dos investigados quanto à diminuição e ausência de professores substitutos nas escolas evidencia uma necessidade trazida pela Estratégia 18.1 do PME de Mariana (Lei 13.042/2015), que prevê necessidade de realização de concurso público, no início do ano de 2018, 
fato que deve considerar o número de remoções e substituições do quadro de professores da rede de ensino.

Outra demanda formativa tratada pelos professores refere-se à relevância dos cursos de formação continuada para a prática docente. Segundo o professor P2, esses cursos devem priorizar:

[...] a formação continuada que realmente atendesse às necessidades do profissional. Porque, buscar cursos de formação continuada, no qual o que vai ser visto é o que a gente já sabe, ou algo que não está dentro das expectativas enquanto educador, não vai adiantar muito. E aí, fica enchendo a gente de coisa que a gente não precisa. Quando, na verdade, a gente tá precisando é de outra coisa. É igual a você dar comida para quem não tem fome e deixar com sede quem precisa de água (P2).

Ainda para os professores P19 e P21, os cursos não atendem suas demandas formativas, configurando-se como repetitivos e distanciados de suas expectativas.

Então, assim: uma formação pra gente ela tem de atender todas essas demandas que a gente precisa. Que é difícil, né? (P19).

Mas normalmente, a maioria desses cursos que nós fazemos é uma repetição do curso anterior. Não muda o assunto [...]. Você não tem um retorno dos seus anseios (P21).

Infere-se das falas dos professores, que formar-se é mais do que receber ou obter informações e compreendê-las, mas tornar o aprendizado parte dos seus interesses, anseios e necessidades e, assim, desenvolver-se com ele. Importante frisar, que a formação continuada, como processo de desenvolvimento profissional, não se restringe a uma instituição ou a um curso específico, tendo em vista que os professores se desenvolvem principalmente no contexto do trabalho exercido na escola. E, ainda, esse mesmo contexto depende de relações com outras instâncias, como o Estado em suas diferentes representações, a exemplo da família e das organizações instituídas para que a escola se desenvolva. Para Gatti (2008) o termo formação continuada, na perspectiva de desenvolvimento profissional dos professores, deve ser:

Tomado de modo amplo e genérico, como compreendendo qualquer tipo de atividade que venha a contribuir para o desempenho profissional - horas de trabalho coletivo na escola, reuniões pedagógicas, trocas cotidianas com os pares, participação na gestão escolar, congressos, seminários, cursos de diversas naturezas e formatos, oferecidos pelas Secretarias de Educação ou outras instituições para pessoal em exercício nos sistemas de ensino, relações profissionais virtuais, processos diversos a distância (vídeo ou teleconferências, cursos via internet etc.), grupos de sensibilização profissional, enfim, tudo que possa oferecer ocasião de informação, reflexão, discussão e trocas que favoreçam o aprimoramento profissional, em qualquer de seus ângulos, em qualquer situação. (GATTI, 2008, p. 57)

Nas práticas dos cursos de formação de professores, é comum se valorizar a transmissão de teorias que privilegia somente alguns pensamentos ideologicamente dominantes, em detrimento da complexidade dos conhecimentos vindos das experiências individuais e coletivas, construídas ao longo da carreira dos professores. Contrariando essa realidade, espera-se que os processos formativos envolvam toda a trajetória desses profissionais, suas concepções de vida, de sociedade, de educação, de escola, suas habilidades, seus interesses, suas necessidades, como também seus medos, dificuldades, desafios e limitações. Caso contrário, se caracterizarão como cursos sem sentido e "repetitivos", termo refletido anteriormente na fala do professor P21. 
Ao pensar na qualidade da oferta dos cursos de formação continuada direcionados aos professores, deve-se observar qual concepção de formação se encontram por trás dessa oferta. Ao longo da história da educação e de sua própria trajetória, alguns desses cursos de formação vêm desenvolvendo várias concepções e práticas, com acentuada influência ideológica, geográfica, acadêmica, econômica e política. Contudo, nota-se que por muito tempo e ainda nos dias atuais, a maioria dessas concepções compreende a formação continuada como:

[...] uma maneira de suprir as lacunas existentes na formação "inicial" docente; de sanar dificuldades escolares que acontecem no cotidiano escolar; de implantar políticas, programas, projetos, campanhas, principalmente governamentais; de adquirir certificados (créditos) para ascender na carreira e/ou obter benefícios salariais; de satisfazer interesses ou necessidades de conhecimentos específicos, ou seja, cursos de curta duração que contribuem apenas para cumprir uma exigência social (ALVARADO-PRADA, FREITAS; FREITAS, 2010, p. 374).

Frente a essa realidade, o que se percebe no quadro das políticas atuais, com destaque para o novo PNE (Lei 13.005/2014) é o interesse em que as instituições de ensino superior assumam a formação continuada dos professores, o que por várias razões não vem acontecendo. Assim, o que se tem visto é que muitos estados e municípios têm deixado essa formação por conta de empresas, instituições e profissionais, que não atendem as condições necessárias à diversidade de seus requerimentos. Além disso, buscam atender mais os interesses dos gestores públicos, por vezes sem condições para compreender a complexidade desse tipo de formação, do que as demandas formativas dos próprios professores.

Esse tipo de ação, dificilmente provocará algum tipo de mudança na qualidade do processo de ensino e aprendizagem ofertado, tendo em vista que o professor não é considerado como autor de sua própria formação e nem ouvido quanto as suas demandas formativas, sentindo-se desvalorizado. Além disso, desconsidera suas expectativas pessoais e profissionais, suas condições de trabalho e as culturas elaboradas pelas unidades escolares nas quais atuam.

No exame das falas dos professores, percebe-se, também, como a ideia restrita de formação continuada é difundida no meio escolar. Fato que alia esse tipo de formação aos espaços externos à escola, não vendo esta como lócus formativo. Um dos motivos que fortalece esse tipo de pensamento se dá pelo fato de grande parte das escolas não propiciarem momentos de encontros e de trocas de experiências entre os docentes. Os momentos para realização de Atividades Complementares (AC), por exemplo, são bem propícios para essa finalidade, o que incluiria ouvir os docentes quanto as suas demandas formativas, anseios, dúvidas, preocupações e perspectivas. Porém, em grande parte dos casos, o que se percebe é que os momentos de AC são mal aproveitados e desperdiçados com afazeres de ordem burocrática. Em torno dessas ideias, 0 professor P17 traz uma alternativa de curso de formação, que tem a escola como lócus e se aproxima de um modelo desejado por Pereira - Diniz (1999), Gatti (2009) e Imbernón (2004).

Eu acho que o curso, não tem como você falar assim: "olha, você fez e pronto e tá acabado". Eu acho que o curso tinha que ser igual a um grupo de apoio. Você faz aquilo, aí, você vai lá, experimenta, aí, volta e discuti com o grupo de novo e vê o que deu certo, o que não deu certo e, assim, vai e volta. Você fazer um grupo assim para discutir, igual como a gente tá aqui hoje (P17). 
Nesse sentido, "a instituição é vista como um nicho ecológico para o desenvolvimento e a formação. O professor é sujeito e não objeto de formação" (IMBERNÓN, 2004, p. 81). O posicionamento dos docentes e do coordenador pedagógico da escola nesse processo formativo é de extrema importância e terá como objetivo confrontar teoria e prática, suscitando a busca pela reflexão da rotina diária.

Por outro lado, Pereira - Diniz (1999) enfatiza que para a escola ser considerada espaço de formação, é necessário garantir aos professores as condições de trabalho adequadas para a realização do fazer pedagógico. E, assim, tornar-se um espaço coletivo da construção de saberes e práticas. A estreita relação entre a formação e as condições de trabalho pode ser vista nas falas dos professores $\mathrm{P} 7$ e $\mathrm{P} 3$, ao afirmar que:

A gente fez uma pós agora, a gente terminou [...]. Você vê que você aprende. Tem coisa que você consegue praticar em sala, mas você depende da escola, ou do espaço físico, ou do material. Péssimo! Horrível! (P7).

$\mathrm{E}$, mesmo sendo barrado de todas as formas pra conseguir colocar a formação em prática, a gente foi lá e ainda achou uma brechinha que nem água (P3).

Dentre outros quesitos relacionados às boas condições de trabalho, que, por sua vez, estão interligadas a formação docente, pode-se citar: tempo para reflexão e sistematização da prática, bem como para estudos individuais e coletivos e troca de experiências entre os pares.

Diante do contexto apresentado em torno da formação continuada de professores, nota-se que, apesar da: dificuldade de oferta; falta de um programa de formação continuada, por parte da SME; impedimentos na liberação dos docentes; lacuna no quadro de servidores/professores; compreensões equivocadas quanto à concepção de formação continuada; déficit formativo, relacionado à que de tipo de formação os professores consideram relevantes para o seu processo de DPD e; tensa relação entre formação continuada e condições de trabalho, os professores continuam a investir na sua formação de forma autônoma e, por vezes, empenhando sacrifícios. Assim como evidenciam os professores P8, P22, P17 e P3:

Então, cabe a nós procurar, cada um dentro da sua procura. Eu fiz uma segunda pós-graduação, eu tento continuar, tô tentando continuar meus estudos (P8).

Por mais que os cursos de formação que são oferecidos, eles não nos atendam, a gente foi lá e buscou sozinho. A gente não importou de investir o nosso salário ou as nossas horas com família, de sono, pra poder fazer aquilo (P22).

A gente que tem que correr atrás [...]. Então, a gente corre atrás para poder estar trabalhando na sala de aula. Colher, aprender com uns, faz cursos, capacitações e continuar além [...] (P17).

[...]. Eu vejo o que é que eu necessito e vou aprimorando (P3).

Além da formação inicial e dos cursos de formação continuada, existe outra perspectiva de formação docente que requer ser melhor investigada, trata-se da autoformação. Nesta perspectiva, os professores investem em si mesmo e na sua própria formação, a partir do entendimento das suas carências e dificuldades. Pensar a formação para além do formato, normas e procedimentos, que, via de regra, constitui os cursos de formação inicial e/ou continuada requer do professor uma tomada de consciência do profissional que se é, bem como a busca em redescobrir-se enquanto profissional/pessoa. Nessa redescoberta, o professor se torna capaz de ressignificar 0 conhecimento que detém e construir novos saberes. 
Ao apropriar-se do seu próprio conhecimento, ele adquire maior confiança em si mesmo e maior clareza sobre o que ensina, a forma como ensina e por que ensina. Dessa forma, o seu trabalho ascende a um processo permanente de investigação e gera possibilidades de construir novos caminhos e referenciais teórico-práticos importantes à sua formação. Por outro lado, não se pode ignorar a responsabilidade dos sistemas estaduais e municipais de ensino na oferta de formação contínua a esses profissionais.

No enfrentamento das demandas formativas suscitadas pelos professores é preciso que as políticas de formação docente, sobretudo as prevista nas metas 15 e 16 do PNE (Lei 13.005/2014), tenha um olhar centrado nas propostas de formação dos estados e municípios, a fim de que estas tratem esse elemento da vida profissional dos professores de maneira sistêmica. Isto é, articulandoo com: as demandas formativas dos professores, os elementos da carreira e a regulamentação do ensino superior de modo a atender as necessidades da prática do ensino em sala de aula, sem, contudo, afastar-se dos constructos teóricos necessários ao alicerce dessa mesma prática. Assim como, garantindo uma formação continuada ancorada no desenvolvimento profissional dos professores, na melhoria do processo de ensino e aprendizagem e, por conseguinte, da educação básica nacional.

\section{Considerações Finais}

Não resta dúvida que todo projeto educativo que vise à qualidade do processo de ensino e aprendizagem deve ter no processo formativo dos docentes um caminho seguro e promissor. Para Gatti (2016), isto implica em não aligeirar as formações dos professores, o que sugere a construção e efetivação de políticas públicas educacionais que Ihes oportunize uma qualificação com nível adequado para atuar profissionalmente.

O que se percebe diante desse cenário, é que o enorme impulso em torno da formação docente, envolvendo diversas instituições formadoras, públicas e privadas, vem se pautando na ideia de que com os professores graduados em nível superior haverá um salto qualitativo substancial no processo de ensino e aprendizagem da educação básica.

Esse tipo de análise centraliza as políticas de formação inicial docente no país, enfatiza a capacidade solitária da escola em mudar a realidade social imposta e ignora aspectos estruturais do desenvolvimento profissional dos docentes, a exemplo de suas carreiras, valorização e condições de trabalho. O privilégio da formação docente, organizada à margem desses aspectos, realça a imagem do professor como mero transmissor de um saber produzido no exterior de sua profissão.

Como visto ao longo do texto, a trajetória de formação continuada dos professores se revela em torno de vários obstáculos, como a exemplo da falta de valorização docente, tendo em vista que os professores não são apreciados acerca de suas demandas formativas, bem como das dificuldades de oferta e da ausência de incentivo à formação continuada. Mesmo diante desse 
contexto, as análises realizadas indicam que os professores continuam investindo na sua formação de maneira autônoma, ainda que para isso desprendam sacrifícios. A respeito dessa questão, infere-se que a autoformação dos docentes possui um lado positivo, tendo em vista seu crescimento, principalmente por meio do exercício reflexivo de sua prática e das necessidades desta. Entretanto, a perversa contradição dessa situação está entre a ideia do professor como foco principal do sucesso do sistema educacional e a imposição, percebida, em diversas redes de ensino para que estes profissionais, por conta própria e sem apoio, atendam os apelos do governo em "fazer-se competente".

\section{Agradecimentos}

À CAPES (Coordenação de Aperfeiçoamento de Pessoal de Nível Superior) pela concessão de bolsa de mestrado para o desenvolvimento das atividades da pesquisa.

\section{Referências}

ALVARADO-PRADA, Luis Eduardo; FREITAS, Thaís Campos; FREITAS, Cinara Aline. Formação continuada de professores: alguns conceitos, interesses, necessidades e propostas. Revista Diálogo Educação. Curitiba, v. 10, n. 30, p. 367-387, mai/ago. 2010.

BRASIL. Lei no 9.394, de 20 de dezembro de 1996. Estabelece as diretrizes e bases da educação nacional. Brasília, 20 dez. 1996. Disponível em: ‘http://www.planalto.gov.br/ccivil_03/leis/L9394.htm〉. Acesso em: 23 abr. 2016.

. Ministério da Educação. Referenciais para formação de professores. 2ª . ed. Secretaria de Educação Fundamental, Brasília, 2002.

MEC/CNE/CP. Parecer no 05/2005. Diretrizes Curriculares Nacionais para o Curso de

Pedagogia. Disponível em: ‘http://portal.mec.gov.br/cne/arquivos/pdf/pcp05_05.pdf». Acesso em: 17 fev. 2017.

MEC/CNE/CP. Resolução no 01, de 15 de maio de 2006. Institui as Diretrizes

Curriculares Nacionais para o Curso de Graduação em Pedagogia. Disponível em: 〈http://portal.mec.gov.br/cne/arquivos/pdf/rcp01_06.pdf〉. Acesso em: 26 jun. 2016.

. Lei № 13.005, de 25 de junho de 2014. Aprova o Plano Nacional de Educação. Disponível em: ‘http://www.planalto.gov.br/ccivil_03/_ato2011-2014/2014/lei/l13005.htm). Acesso em: 23 abr. 2017.

DAVIS, Claudia Leme Ferreira; NUNES, Marina Muniz Rossa; ALMEIDA, Patrícia Cristina Albieri. Formação continuada de professores: uma análise das modalidades e das práticas em estados e municípios brasileiros. São Paulo: Fundação Carlos Chagas, 2011. 129 p. 
GATTI. Bernadete Angelina. Análise das políticas públicas para formação continuada no Brasil na última década. Revista Brasileira de Educação. Rio de Janeiro, v. 13 n. 37, p. 57 - 70. jan./abr. 2008. Disponível em: ‘http://www.scielo.br/pdf/rbedu/v13n37/06.pdf`. Acesso em: 23 abr. 2017.

Formação de professores: condições e problemas atuais. Revista Brasileira de Formação de Professores. Cristalina, v. 1, n. 1, p.90-102, Mai/2009.

Educação, escola e formação de professores: políticas e impasses. Educar em Revista, Curitiba, n. 50, p. 51-67, out./dez. 2013.

(Org.). O trabalho docente: avaliação, valorização, controvérsias. Campinas, SP: Autores Associados: São Paulo: Fundação Carlos Chagas, 2013. 256 p.

Formação de Professores: Condições e Problemas Atuais. Revista Internacional de Formação de Professores (RIFP), Itapetininga, v. 1, n.2, p. 161-171, 2016. Disponível em: ‘http://itp.ifsp.edu.br/ojs/index.php/RIFP/article/view/347/360). Acesso em: 18 jul.2017.

GATTI, Bernadete Angelina; BARRETO, Elba Siqueira de Sá. Professores do Brasil: impasses e desafios. Brasília: UNESCO, 2009. 294 p.

GATTI, Bernadete Angelina; BARRETO, Elba Siqueira de Sá; ANDRÉ, Marli Eliza Dalmazo de Afonso. Políticas docentes no Brasil: um estado da arte. Brasília: UNESCO, 2011. 300 p.

IMBERNÓN. Francisco. Formação docente e profissional: formar-se para a mudança e a

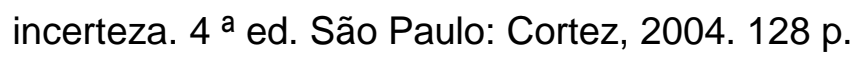

KUENZER, Acácia Zeneida; RODRIGUES, Marli de Fátima Rodrigues. As Diretrizes curriculares para o curso de pedagogia: uma expressão da epistemologia da prática. In: Novas subjetividades, currículos, docência e questões pedagógicas na perspectiva da inclusão social. Encontro Nacional de Didática e Prática de Ensino. Recife: ENDIPE, 2006. p. 185-212.

MARIANA. Plano de Carreira dos Professores Municipais. Lei Complementar n. 139/2014. Dispõe sobre o plano de carreira do pessoal do magistério, secretaria escolar e inspeção de alunos, e do pessoal de monitoria de creche e de monitoria de ensino especial da Secretaria de Educação do município de Mariana. Mariana: Prefeitura Municipal, 2014. Disponível em: ‘http://funprevmariana.com.br/uploads/funprev_2014/PLANO\%20CARREIRA\%20EDUCA\%C3\%87 \%C3\%830/Lei_Complementar_nu00BA_139_-_Plano_Carreira_EDUCAu00C7u00C3O2.pdf. Acesso em: 05 mai. 2016.

Plano Municipal de Educação de Mariana - MG. Lei № 3.042/2015. Aprova o Plano Municipal de Educação de Mariana. Mariana: Prefeitura Municipal, 2014. Disponível em: ‘http://www.camarademariana.mg.gov.br/uploads/camara_mariana_2014/camara/legislacao/lei-n3-042-parte-1-compressed.pdf). Acesso em: 20 de mar. 2016.

NÓVOA. Antonio. Os professores e as histórias da sua vida. In: NÓVOA, Antonio. (Org.). Vida de professores. 2ed. Porto: Porto Editora, 1995. 215 p.

PEREIRA-DINIZ. Júlio Emílio. As licenciaturas e as novas políticas educacionais para a formação docente. Revista Educação e Sociedade. Campinas, v.20, n.68, p. 109-125, dez. 1999. 
Disponível

em:

‘http://www.scielo.br/scielo.php?script=sci_arttext\&pid=S0101-

73301999000300006, Acesso em: 12 dez. 2016.

RAMALHO, Betania Leite; NUÑEZ, Isaro Beltrán; GAUTHIER, Clermont. Formar o professor, profissionalizar o ensino - perspectivas e desafios. Porto Alegre: Sulina, 2003. 208 p.

SCHEIBE. Leda. Valorização e formação dos professores par a educação básica: questões desafiadoras para um novo Plano Nacional de Educação. Revista Educação e Sociedade. Campinas, v. 31, n. 112, p. 981-1000, jul-set. 2010. Disponível em: ‘http://www.cedes.unicamp.br/〉. Acesso em: 23 abr. 2017. 